\title{
Genetic and biochemical analyses of chromosome and plasmid gene homologues encoding ICL and ArCP domains in Vibrio anguillarum strain $\mathbf{7 7 5}$
}

\author{
Manuela Di Lorenzo • Michiel Stork • \\ Jorge H. Crosa
}

Received: 16 December 2010/ Accepted: 10 January 2011/Published online: 1 February 2011

(C) Springer Science+Business Media, LLC. 2011

\begin{abstract}
Anguibactin, the siderophore produced by Vibrio anguillarum 775 is synthesized from 2,3-dihydroxybenzoic acid (DHBA), cysteine and hydroxyhistamine via a nonribosomal peptide synthetase (NRPS) mechanism. Most of the genes encoding anguibactin biosynthetic proteins are harbored by the pJM1 plasmid. In this work we report the identification of a homologue of the plasmidencoded $a n g B$ on the chromosome of strain 775 . The product of both genes harbor an isochorismate lyase (ICL) domain that converts isochorismic acid to 2,3dihydro-2,3-dihydroxybenzoic acid, one of the steps of DHBA synthesis. We show in this work that both ICL domains are functional in the production of DHBA in $V$. anguillarum as well as in E. coli. Substitution by alanine of the aspartic acid residue in the active site of both ICL domains completely abolishes their isochorismate lyase activity in vivo. The two proteins also carry an aryl carrier protein
\end{abstract}

M. Di Lorenzo $(\varangle)$

Department of Microbial Ecology, Netherlands Institute of Ecology, Wageninegen, The Netherlands

e-mail: M.diLorenzo@nioo.knaw.nl

M. Stork

Department of Molecular Microbiology, Utrecht

University, Utrecht, The Netherlands

\section{J. H. Crosa}

Department of Molecular Microbiology and Immunology, Oregon Health and Science University, Portland,

OR 97239-3098, USA
(ArCP) domain. In contrast with the ICL domains only the plasmid encoded ArCP can participate in anguibactin production as determined by complementation analyses and site-directed mutagenesis in the active site of the plasmid encoded protein, S248A. The site-directed mutants, D37A in the ICL domain and S248A in the ArCP domain of the plasmid encoded AngB were also tested in vitro and clearly show the importance of each residue for the domain function and that each domain operates independently.

Keywords Iron $\cdot$ Siderophore $\cdot$ Nonribosomal peptide synthetase $\cdot 2$,3-dihydroxybenzoic acid . Isochorismate lyase domain - Aryl carrier protein domain

\section{Introduction}

Vibrio anguillarum is a marine bacterium responsible for both marine and freshwater fish epizootics throughout the world (Actis et al. 1999). Many serotype $\mathrm{O} 1$ strains of $V$. anguillarum possess the $65 \mathrm{~kb}$ virulence plasmid pJM1 or pJM1-like plasmids encoding an iron-scavenging system, which is essential for virulence in this bacterium (Conchas et al. 1991; Crosa 1980; Di Lorenzo et al. 2003; Tolmasky et al. 1988a, b). This system includes a low- 
molecular-weight iron-binding compound, anguibactin, which once secreted, competes for bound iron within the host fish (Actis et al. 1988; Wolf and Crosa 1986). The iron-anguibactin complex is then internalized by a transport system that includes the FatA, $-\mathrm{B},-\mathrm{C}$, and $-\mathrm{D}$ proteins and requires the TonB2 complex for energy-transduction to the outer membrane (Actis et al. 1988; Stork et al. 2004). Anguibactin possesses both a catechol and a hydroxamate group and it has been characterized as $\omega$ - $N$-hydroxy- $\omega-N$ (( $2^{\prime}-\left(2^{\prime \prime}, 3^{\prime \prime}\right.$-dihydroxyphenyl)thiazolin-4'-yl)carboxy) histamine by crystal X-ray diffraction studies and chemical analysis (Jalal et al. 1989). Retrobiosynthesis and experimental data showed that anguibactin is synthesized from 2,3-dihydroxybenzoic acid (DHBA), cysteine, and hydroxyhistamine (Di Lorenzo et al. 2004a).

The genes encoding proteins involved in the biosynthesis and transport of anguibactin lie on a $25 \mathrm{~kb}$ contiguous region of the virulence plasmid (Tolmasky et al. 1988a). An additional gene cluster was identified in a non-contiguous region of pJM1 and the products encoded by the genes in this cluster are homologues of enzymes involved in the biosynthesis and activation of DHBA (Di Lorenzo et al. 2003). We have also reported the presence of this cluster in the pJM1-like plasmid pJHC-1 of strain 531A including the gene encoding the bi-functional AngB protein: its amino end conferring an isochorismate lyase activity required for the production of DHBA and its carboxyl end providing an aryl carrier protein domain, functioning in anguibactin assembly (Welch et al. 2000). Furthermore, the carboxyterminal end of AngB can be synthesized from the $3^{\prime}$ region of $\operatorname{ang} B$, as an independent polypeptide which, like the carboxy terminal portion of AngB, also functions as an aryl carrier protein involved in anguibactin assembly (Welch et al. 2000). This pJHC1 plasmid-mediated angB gene is essential not only for anguibactin biosynthesis but also for the production of DHBA in the 531A strain since when this strain was cured of the pJM1-like plasmid pJHC1, resulting in strain S531A-1, it could no longer produce DHBA (Welch et al. 2000). Previous work in our laboratory had shown that the prototypic strain 775 when cured of the pJM1 plasmid, generating plasmidless strain H775-3, still produced DHBA (Chen et al. 1994). Recently a partial sequence of an open reading frame (orf) with homology to the plasmid-encoded angB gene was identified in the chromosomal DNA of $V$. anguillarum 775 within a gene cluster encoding vanchrobactin biosynthesis and transport genes (Alice et al. 2005; Balado et al. 2006; Naka et al. 2008). We report in this work the complete sequence of this chromosomal gene, $v a b B$, from strain 775 and the analyses of its domains as compared to the plasmid-encoded version. Our results also explain the phenotypic differences in DHBA production between the 531A and 775 strains of $V$. anguillarum.

\section{Materials and methods}

Bacterial strains and plasmids

Bacterial strains and plasmids used in this study are described in Table 1. V. anguillarum was cultured at $25^{\circ} \mathrm{C}$ in either trypticase soy broth or agar supplemented with $1 \% \mathrm{NaCl}$ (TSBS and TSAS, respectively). For experiments to determine iron uptake characteristics, the strains were first grown on TSAS supplemented with the appropriate antibiotics and then in M9 minimal medium (Sambrook and Russell 2001) supplemented with $0.2 \%$ Casamino acid, $5 \%$ $\mathrm{NaCl}$, the appropriate antibiotics and either ethylenediamine-di-(o-hydroxyphenyl acetic acid) (EDDA) for iron-limiting condition or ferric ammonium citrate (FAC) for iron-rich conditions. Antibiotic concentrations used for $V$. anguillarum were ampicillin (Ap) $500-800 \mu \mathrm{g} / \mathrm{ml}$, rifampicin (Rif) $100 \mu \mathrm{g} / \mathrm{ml}$, spectinomycin (Sp) $100 \mu \mathrm{g} / \mathrm{ml}$, chloramphenicol (Cm) $10-15 \mu \mathrm{g} / \mathrm{ml}$ and kanamycin $(\mathrm{Km}) 100-200 \mu \mathrm{g} / \mathrm{ml}$.

E. coli strains were grown in Luria-Bertani (LB) medium in the presence of the appropriate antibiotics. Antibiotic concentrations used for E. coli were Ap $100 \mu \mathrm{g} / \mathrm{ml}$, Sp $100 \mu \mathrm{g} / \mathrm{ml}, \mathrm{Cm} 30 \mu \mathrm{g} / \mathrm{ml}, \mathrm{Km} 50 \mu \mathrm{g} / \mathrm{ml}$ and trimethoprim (Tp) $10 \mu \mathrm{g} / \mathrm{ml}$.

General methods

Plasmid DNA preparations were performed using the alkaline lysis method (Sambrook and Russell 2001). Sequence quality plasmid DNA was generated using Wizard $^{\circledR}$ Plus SV Minipreps (Promega). Restriction endonuclease digestion of DNA was performed under the conditions recommended by the supplier (Invitrogen, Roche, NEB). Transformations in the E. coli 
Table 1 Strains and plasmids used in this study

\begin{tabular}{|c|c|c|}
\hline Bacterial strains & Genotype and relevant characteristics & Source or reference \\
\hline \multicolumn{3}{|l|}{ Vibrio anguillarum } \\
\hline 775(pJM1) & Wild type; Pacific ocean prototype & Crosa et al. (1980) \\
\hline $531 \mathrm{~A}(\mathrm{pJHC} 1)$ & Wild type; Atlantic ocean prototype & Tolmasky et al. (1988b) \\
\hline 775(pJM1::囚) & $\begin{array}{l}775 \text { carrying pJM1 with } \Omega \text { transcription-translation terminator } \\
\text { at the } B g l I I \text { site in } \operatorname{ang} B\end{array}$ & This study \\
\hline 775(pJM1::K) & $\begin{array}{l}775 \text { carrying pJM } 1 \text { with a Klenow modification at the } B g l I I \text { site } \\
\text { in angB }\end{array}$ & This study \\
\hline $775 v a b B:: \mathrm{Cm}$ & $\begin{array}{l}775 \text { with the } v a b B \text { gene replaced by the chloramphenicol } \\
\text { resistance cassette gene }\end{array}$ & This study \\
\hline $775 v a b B:: \mathrm{Cm}(\mathrm{pJM} 1:: \Omega)$ & $\begin{array}{l}775 \text { with the } v a b B \text { gene replaced by the chloramphenicol } \\
\text { resistance cassette gene, carrying pJM } 1 \text { with } \Omega \text { transcription- } \\
\text { translation terminator at the } B g l I I \text { site in angB }\end{array}$ & This study \\
\hline $775 v a b B:: \mathrm{Cm}(\mathrm{pJM} 1:: \mathrm{K})$ & $\begin{array}{l}775 \text { with the } v a b B \text { gene replaced by the chloramphenicol } \\
\text { resistance cassette gene, carrying pJM1 with a Klenow } \\
\text { modification at the } B g l \text { II site in } a n g B\end{array}$ & This study \\
\hline CC9-16(pJHC9-16) & Anguibactin-deficient, iron transport-proficient & Walter et al. (1983) \\
\hline CC9-8(pJHC9-8) & Anguibactin-deficient, iron transport-deficient & Walter et al. (1983) \\
\hline \multicolumn{3}{|l|}{ Escherichia coli } \\
\hline XL1 blue & $\begin{array}{l}\text { recA1, endA1, gyrA46, thi, hsdR17, supE44, relA, lac } \mathrm{F}^{\prime} \\
\quad\left[\text { proAB }^{+}, \text {lacI }^{q}, \text { lacZ } Z M 15 \text { Tn } 10\left(\text { tet }^{\mathrm{r}}\right)\right]\end{array}$ & Stratagene \\
\hline HB101 & $\begin{array}{l}\text { supE44 hsd20 }\left(r^{-B} m^{-B}\right) \text { recA13 ara-14 proA2 lacY1 galK2 } \\
\quad \text { rpsL20 xyl-5 mtl-1 }\end{array}$ & Boyer and Roulland-Dussoix (1969) \\
\hline $\mathrm{BLR}(\mathrm{DE} 3)$ & $\begin{array}{l}\mathrm{F}^{-} \text {ompT } h s d S^{B}\left(r^{-B} m^{-B}\right) \text { gal dcm } \Delta(\operatorname{srl}-r e c A) 306:: \operatorname{Tn} 10\left(\text { tet }^{\mathrm{B}}\right) \\
\quad(\mathrm{DE} 3)\end{array}$ & Novagen \\
\hline AN192 & $\begin{array}{l}\text { proC14 leu-6 trpE38 thi-1 fhuA23 lacY1 mtl-1 xyl-5 rpsL109 } \\
\text { azi-6 tsx-67 entB402 }\end{array}$ & Staab and Earhart (1990) \\
\hline \multicolumn{3}{|l|}{ Salmonella typhimurium } \\
\hline$e n b-1$ & LT2 derivative, enterobactin ${ }^{-}, \mathrm{Sm}^{\mathrm{r}}$ & Pollack and Neilands (1970) \\
\hline$e n b-7$ & LT2 derivative, enterobactin ${ }^{-}, \mathrm{DHBA}^{-}, \mathrm{Sm}^{\mathrm{r}}$ & Pollack and Neilands (1970) \\
\hline \multicolumn{3}{|l|}{ Plasmids } \\
\hline pJM1 & Indigenous plasmid in strain 775 & Crosa et al. (1980) \\
\hline $\mathrm{pJHC1}$ & Indigenous plasmid in strain $531 \mathrm{~A}$ & Tolmasky et al. (1988b) \\
\hline pJHC9-16 & pJM1 derivative carrying TAF and transport genes, & Tolmasky et al. $(1988 a, b)$ \\
\hline pJHC9-8 & pJM1 derivative carrying only the TAF region & Tolmasky et al. $(1988 \mathrm{a}, \mathrm{b})$ \\
\hline pRK2073 & Helper plasmid for conjugation, $\mathrm{Tp}^{\mathrm{r}}, \mathrm{Tra}^{+}$ & Figurski and Helinski (1979) \\
\hline $\mathrm{pCR}^{\circledR} 2.1-\mathrm{TOPO}^{\circledR}$ & Cloning vector, $\mathrm{Ap}^{\mathrm{r}}, \mathrm{Km}^{\mathrm{r}}$ & Invitrogen \\
\hline SuperCos 1 & Cosmid vector, $\mathrm{Ap}^{\mathrm{r}}$ & Stratagene \\
\hline pTW-MEV & Suicide vector, R6K ori, $s a c B, \mathrm{Ap}^{\mathrm{r}}$ & Welch et al. (2000) \\
\hline pTW99 & $\begin{array}{l}\text { pBR322 with kanamycin resistance gene from pUC4K cloned } \\
\text { in SalI site }\end{array}$ & Welch et al. (2000) \\
\hline pBR322 & Cloning vector, $\mathrm{Tc}^{\mathrm{r}}, \mathrm{Ap}^{\mathrm{r}}$ & Bolivar (1978) \\
\hline pKD46 & pSC101 oriTS, $\mathrm{P}_{\mathrm{araB}} g$ b exo, $\mathrm{Ap}^{\mathrm{r}}$ & Datsenko and Wanner (2000) \\
\hline pKD3 & R6K ori, $\mathrm{Cm}^{\mathrm{r}}, \mathrm{Ap}^{\mathrm{r}}$ & Datsenko and Wanner (2000) \\
\hline pQE60 & T5 phage promoter expression vector, $\mathrm{Ap}^{\mathrm{r}}$ & Qiagen \\
\hline pET29b & $\mathrm{T} 7$ phage promoter expression vector, $\mathrm{Km}^{\mathrm{r}}$ & Novagen \\
\hline Cos\#2 & $\begin{array}{l}\text { SuperCos } 1 \text { harboring a } 15 \mathrm{~kb} \text { fragment from } 775 \text { genomic } \\
\text { DNA }\end{array}$ & Lab collection \\
\hline
\end{tabular}


Table 1 continued

\begin{tabular}{lll}
\hline Bacterial strains & Genotype and relevant characteristics & Source or reference \\
\hline pAngB & $\begin{array}{l}\text { angB gene of plasmid pJM1 cloned by PCR in pTW99 } \\
\text { pCR- } v a b B\end{array}$ & $\begin{array}{l}\text { This study } \\
\text { vabB gene cloned in pCR }{ }^{\circledR} 2.1-\text { TOPO }^{\circledR}\end{array}$ \\
pVabB & ClaI-BamHI fragment from pCR-vabB cloned in pBR322 & This study \\
pAngB-D37A & pAngB with mutation D37A in ICL domain & This study \\
pVabB-D71A & pVabB with mutation D71A in ICL domain & This study \\
pAngB-S248A & pAngB with mutation S248A in ArCP domain & This study \\
pQEAngB & angB cloned as a NcoI- $B g l$ II fragment in pQE60 & This study \\
pQEAngB-D37A & pQEAngB with mutation D37A in ICL domain & This study \\
pQEAngB-S248A & pQEAngB with mutation S248A in ArCP domain & This study \\
pEntC & entC cloned in pET29b & This study \\
pVibE & vibE cloned in pET29b & Keating et al. (2000) \\
pSfp & $s f p$ cloned in pET29b & C. T. Walsh \\
\hline
\end{tabular}

strains HB101, XL1 blue and BLR(DE3) and other cloning strategies were performed according to standard protocols (Sambrook and Russell 2001). DNA sequencing reactions were carried out by the OHSUMMI Research Core Facility (http://www.ohsu.edu/ core) using a model 377 Applied Biosystems Inc. automated fluorescence sequencer. Sequencing primers were designed using Oligo $6.8^{\circledR}$ primer analysis software and purchased from the OHSU-MMI Research Core Facility (http://www.ohsu.edu/core) and Invitrogen. DNA and protein sequence analysis were carried out at the NCBI using the BLAST network service (Altschul et al. 1990). The web server Tcoffee (http://igs-server.cnrs-mrs.fr/Tcoffee/tcoffee_cgi/ index.cgi) was used for multiple sequence alignment (Notredame et al. 2000). Three-dimensional models of the ArCP domains of AngB and VabB were built using the web server 3D-JIGSAW (http://3djigsaw.com/).

Plasmids were transferred from $E$. coli to $V$. anguillarum by triparental conjugation as previously described (Tolmasky et al. 1988a).

Construction of the complementing clone

The fragment containing the $a n g B$ gene from the pJM1 plasmid was amplified by PCR and cloned into the pBR322 derivative pTW99 as previously described for the $\operatorname{ang} B$ gene of plasmid pJHC1 (Welch et al. 2000). The generated construct, pAngB, was sequenced to confirm that the $a n g B$ gene sequence was not mutated during the PCR amplification or the cloning. A $1.1 \mathrm{~kb}$ fragment containing the chromosomal $v a b B$ gene of strain 775 was amplified by PCR using the VabB-ClaIF (5'-CAATCGATTTTTATGCGTAGAC- ${ }^{\prime}$ ) and the VabB-BamHIR (5'-AGTGGATCCGGTATACTCA AA- $3^{\prime}$ ) primers and genomic DNA from 775 as a template. The forward and the reverse primers were modified to contain restriction endonuclease sites (underlined in the sequence) suitable for cloning downstream of the promoter of the tetracycline resistance gene of pBR322. Reactions consisted of $3 \mathrm{~min}$ at $95^{\circ} \mathrm{C}$ followed by 30 cycles of $45 \mathrm{~s}$ at $94^{\circ} \mathrm{C}, 1 \mathrm{~min}$ at $55^{\circ} \mathrm{C}$, and $2 \mathrm{~min}$ at $72^{\circ} \mathrm{C}$ followed by a single cycle at $72^{\circ} \mathrm{C}$ for $10 \mathrm{~min}$. The PCR product was cloned in the $\mathrm{pCR}^{\circledR} 2.1$-TOPO ${ }^{\circledR}$ vector using the TOPO TA PCR Cloning Kit (Invitrogen). The $1.1 \mathrm{~kb}$ ClaI-BamHI fragment was subcloned into the ClaI-BamHI sites of pBR322 to generate the pVabB plasmid carrying the $v a b B$ gene. After recloning in pBR322 the entire $v a b B$ gene was sequenced to verify that no mutation was generated in the gene during amplification or cloning.

Site-directed mutagenesis

Site-directed mutants were generated using the Quickchange $^{\mathrm{TM}}$ site-directed mutagenesis kit (Stratagene). Plasmids pAngB and $\mathrm{pVabB}$ as template and the primer pairs D37A-U (5'-TCGGTTGTTCTAGT TCACGCTTTACAGGCTTATTTTCTCA-3')/D37 A-L (5'-TGAGAAAATAAGCCTGTAAAGCGTGA ACTAGAACAACCGA-3') and D71A-U (5'-GCG GTACTGCTCATTCACGCTATGCAAAAGTACTT 
TATCA-3')/D71A-L (5'-TGATAAAGTACTTTTGC ATAGCGTGAATGAGCAGTACCGC- $3^{\prime}$ ) were used for the mutation in the ICL domain of the plasmid (pAngB-D37A) and chromosomal (pVabB-D71A) copy, respectively. For the mutant in the ArCP of the plasmid copy primers S248A-U (5'-TGATTTT CCTTGGACTTGATGCGATACGCATAATGACA CT- $3^{\prime}$ ) and S248A-L (5'-AGTGTCATTATGCGTAT CGCATCAAGTCCAAGGAAAATCA- ${ }^{\prime}$ ) were used with plasmid $\mathrm{pAngB}$ as template to generate pAngB$\mathrm{S} 248 \mathrm{~A}$. The procedure was performed according to the manufacturer recommendations, with 16 cycles consisting of: $30 \mathrm{~s}$ at $95^{\circ} \mathrm{C}$ followed by $1 \mathrm{~min}$ at $55^{\circ} \mathrm{C}$ and $12 \mathrm{~min}$ at $68^{\circ} \mathrm{C}$. For the amplification, $P f u$ polymerase was used and after the PCR, the mixture was treated with $D p n I$ to cleave the parental DNA. Then $1 \mu \mathrm{l}$ of the mixture was transformed in the XL1 blue chemically competent cells provided with the Quickchange $^{\mathrm{TM}}$ kit. Site-specific mutations were confirmed by DNA sequencing with the appropriate primers and the entire mutant genes ( $a n g B$ or $v a b B$ ) were sequenced to verify that no other region was affected during mutagenesis.

Construction of $V$. anguillarum mutant strains by allelic-exchange

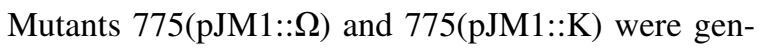
erated as previously described by Welch et al. (2000), employing the suicide vector pTW-MEV harboring either the ang $B:: \Omega$ or the ang $B:: \mathrm{K}$ mutation.

To construct mutant $775 \mathrm{vabB}:: \mathrm{Cm}$, the $v a b B$ gene was replaced with the chloramphenicol resistance cassette in the cosmid vector Supercos harboring a $15 \mathrm{~kb}$ insert containing the $v a b B$ gene (Cos\#2) using the $\lambda$ red system (15). The chloramphenicol acetyl transferase (cat) gene was amplified from plasmid pKD3 with primers $v a b B$-P1 (5'-GGCTTTAAGGCATCACGAACGAGAAAAGCCTCTTTTAAC AG TGTAGGCTGGAGCTGCTTC- $\left.3^{\prime}\right)$ and $v a b B-\mathrm{P} 2\left(5^{\prime}-\right.$ AACTGGTTGCTCTTCAGT AGAACGCGTGTCC GTTACTTGACATATGAATATCCTCCTTAG-3') that have 40 bases of homology to the $v a b B$ sequence at their $5^{\prime}$-end and 20 bases of homology with pKD3 at the $3^{\prime}$-end. The PCR product was transferred by electroporation in HB101 cells harboring Cos\#2 and pKD46. Cells were made electro-competent by washing the cells grown in the presence of arabinose $(0.2 \%)$ four times with ice-cold sterile water at $0^{\circ} \mathrm{C}$.
After electroporation, cells were plated on LB plates containing $\mathrm{Cm}$ at $37^{\circ} \mathrm{C}$. At this temperature the pKD46 plasmid is lost and only cells containing Cos\#2 where the $v a b B$ sequence is replaced with the cat gene are able to grow. Plasmid isolation and restriction digest was performed to assure no rearrangements occurred during the mutagenesis. The NotI fragment containing the entire insert from the cosmid was cloned in vector pTW-MEV. The $v a b B$ knock-out was obtained using the pTW-MEV vector containing $v a b B:: \mathrm{Cm}$, as described for the plasmid mutants. The same procedure was repeated in $775(\mathrm{pJM} 1:: \Omega)$ and $775(\mathrm{pJM} 1:: \mathrm{K})$ strains to obtain the double mutants.

Determination of DHBA and anguibactin production

DHBA was assayed by employing the Arnow reaction for cathecols (Arnow 1937). In addition, a growth assay with Salmonella strains that require DHBA, was used to confirm the presence of this catechol (Pollack and Neilands 1970).

The siderophore anguibactin was detected by three methods. Chrome azurol S (CAS) plates were used to test production of iron-binding compounds by each strain (Schwyn and Neilands 1987). The results obtained on CAS plates were confirmed by a bioassay using strains CC9-16 and CC9-8 that detect specifically anguibactin synthesis, as previously described (Tolmasky et al. 1988a; Walter et al. 1983). Furthermore, strains were tested for sensitivity to the ironchelating compound EDDA via growth assay in liquid minimal medium.

AngB protein expression and purification

The complete angB gene was cloned in the expression vector pQE60 under the control of the T5 promoter (pQEAngB). Cloning into the BglII site of pQE60 adds a $C$-terminal hexahistidine tag and two extra amino acids to the overexpressed protein (GSHHHHHH). Site-directed mutations in the overexpression clone were generated as described above using primer pairs D37A-U/D37A-L (pQEAngBD37A) and S248A-U/S248A-L (pQEAngB-S248A), the $a n g B$ gene cloned in pQE60 as template. The AngB proteins were purified from E. coli XL1 blue containing the expression vector. Cultures were 
grown in LB broth supplemented with $\mathrm{Ap}$ at $37^{\circ} \mathrm{C}$ to an $\mathrm{OD}_{600}$ of 0.3 and then cooled to room temperature. Gene expression was induced with $100 \mathrm{mM}$ isopropyl-b-D-thiogalactopyranoside (IPTG) at $25^{\circ} \mathrm{C}$ for $4 \mathrm{~h}$. The harvested cells were resuspended in $25 \mathrm{mM}$ Tris, $\mathrm{pH} 8.0,300 \mathrm{mM} \mathrm{NaCl}$ and $2 \mathrm{mM} \mathrm{MgCl} 2$, lysed by sonication and the lysate clarified by centrifugation. The supernatant was incubated with Qiagen $\mathrm{Ni}-\mathrm{NTA}$ Superflow resin for $16 \mathrm{~h}$ at $4^{\circ} \mathrm{C}$. Proteins were eluted with a step gradient of five column volumes of lysis buffer containing 25-200 mM imidazole in $25 \mathrm{mM}$ increments. Fractions containing purified AngB proteins (as determined by 12\% SDSPAGE analysis) were pooled and dialyzed against $20 \mathrm{mM}$ Tris, $\mathrm{pH} 8.0,50 \mathrm{mM} \mathrm{NaCl}, 2 \mathrm{mM} \mathrm{MgCl}_{2}$, $1 \mathrm{mM}$ DTT and $10 \%$ glycerol. Samples were concentrated using a Centricon YM-3 (Amicon) and quantified from absorbance at $280 \mathrm{~nm}$ using the predicted molar extinction coefficient $\mathrm{e}=48790$ (http://au.expasy.org/tools/protparam.html).

Expression and purification of EntC, Sfp and VibE

The entC gene was amplified from $E$. coli HB101 genomic DNA using primers EntC-NdeI (5'-TGTGGAGGATCATATGGATA-3') and EntC-XhoI (5'CTCGCTCGAGATGCAA TCCA-3') and cloned in the corresponding sites of the expression vector pET29b. The resulting plasmid pEntC expressed the EntC protein as a translational fusion of a $C$-terminal hexahistidine tag. The construct was transferred to strain BLR(DE3) for expression. EntC was expressed and purified as described above for AngB with few modifications. Cells were grown in LB broth supplemented with kanamycin at $37^{\circ} \mathrm{C}$ to an $\mathrm{OD}_{600}$ of 0.5 prior inductions with $500 \mathrm{mM}$ IPTG. Harvested cells were resuspended in $50 \mathrm{mM}$ Tris, $\mathrm{pH} 8.0,300 \mathrm{mM}$ $\mathrm{NaCl}$ and $20 \mathrm{mM}$ b-mercaptoethanol and then disrupted by sonication.

The construct overexpressing the Sfp and the VibE proteins as translational fusions to $C$-terminal hexahistidine tags were received from the laboratory of Professor Christopher T. Walsh (Harvard Medical School). VibE was expressed and purified as previously described (Keating et al. 2000). Sfp was expressed and purified following the same procedure of the AngB proteins with minor modification. Strain BLR(DE3) harboring pSfp was cultured in LB broth supplemented with kanamycin at $37^{\circ} \mathrm{C}$ to an $\mathrm{OD}_{600}$ of 0.6 prior induction with $1 \mathrm{mM}$ IPTG for $5 \mathrm{~h}$ at $25^{\circ} \mathrm{C}$.

Assay for isochorismate lyase activity

Isochorismate lyase activity of the ICL domain of the AngB protein was determined by a coupled assay with L-lactate dehydrogenase, LDH (Rusnak et al. 1990). In this assay the concentration of pyruvate in the reaction mixture was calculated from the decrease of absorbance at $340 \mathrm{~nm}$ due to NADH oxidation. Pyruvate and 2,3-dihydro-2,3-dihydroxybenzoic acid are formed from isochorismic acid in equimolar amounts in the reaction catalyzed by isochorismate lyases. EntC catalyzes the conversion of chorismic acid to isochorismic acid, the substrate of the ICL domain. Reaction mixtures contained $100 \mathrm{mM}$ Tris, $\mathrm{pH} 7.5,6 \mathrm{mM} \mathrm{MgCl}_{2}, 1.3 \mathrm{mM}$ chorismic acid, $76 \mathrm{nM}$ EntC, $80 \mathrm{nM}$ AngB (wild type and mutant proteins), $0.2 \mathrm{mM} \mathrm{NADH}$ and 7 units of $\mathrm{LDH}$. The reaction mixtures were incubated at $25^{\circ} \mathrm{C}$ for $40 \mathrm{~min}$ and the $\mathrm{OD}_{340}$ measured every $5 \mathrm{~min}$. After $40 \mathrm{~min}$, virtually all the NADH was oxidized in the reaction mixtures containing an active ICL domain.

Analysis of covalent $\left[{ }^{14} \mathrm{C}\right]$ salicylation of the ArCP domain

Reaction mixtures contained $75 \mathrm{mM}$ Tris, $\mathrm{pH}$ 7.5, $10 \mathrm{mM} \mathrm{MgCl}_{2}, 2 \mathrm{mM}$ tris(carboxyethyl)phosphine (TCEP), $200 \mathrm{mM}$ Coenzyme A, $1 \mathrm{mM}$ Sfp (the phosphopantetheinyl transferase) and $10 \mathrm{mM}$ AngB (wild type and mutant proteins). After $1 \mathrm{~h}$ incubation at $25^{\circ} \mathrm{C}$ to obtain holo-AngB, $10 \mathrm{mM} \mathrm{ATP}, 100 \mathrm{mM}$ $\left[{ }^{14} \mathrm{C}\right]$ salicylate and $1 \mathrm{mM}$ VibE (adenylation enzyme) were added to the mixtures and the samples were incubated at $25^{\circ} \mathrm{C}$ for additional $60 \mathrm{~min}$ before precipitation with $10 \%$ trichloroacetic acid (TCA) and $60 \mathrm{mg}$ of BSA. Pellets were washed twice with $10 \%$ TCA, redissolved in $88 \%$ formic acid and submitted for liquid scintillation counting. The percentage of label protein was calculated from the cpm, the specific activity of $\left[{ }^{14} \mathrm{C}\right]$ salicylate and the moles of AngB protein present in the reaction (Marshall et al. 2002).

The accessory proteins Sfp and VibE used in this assay are not the proteins specific for the AngB protein and the anguibactin system. It was previously shown that Sfp and VibE work to high efficiency in 
the phosphopantetheinylation of AngB and activation of the substrate to be loaded on AngB (Marshall et al. 2002). Salycilate is not the actual substrate for VibE or AngB but it was shown to work in this system and the natural substrate DHBA is not available in radioactive-labeled form (Marshall et al. 2002).

Nucleotide sequences accession number

The GenBank accession numbers for the sequences were as follows: for angB, AY312585 for strain 775 and AF311973 for strain 531A; for entC, M36700.

The sequences of the $v a b B$ genes of 775 and $531 \mathrm{~A}$ strains were deposited with GenBank and assigned the accession numbers DQ066620 and DQ066621.

\section{Results}

Identification of a chromosomal $\operatorname{ang} B$ homologue in strain 775

Previous work in our laboratory had shown that strain 775 of $V$. anguillarum when cured of the pJM1 plasmid (H775-3) still produced 2,3-dihydroxybenzoic acid, DHBA (Chen et al. 1994). On the contrary the plasmid-less strain derivative of 531A (S531A-1) could no longer produce DHBA (Welch et al. 2000). Furthermore, it was also shown that in the 531A strain only one of the genes of the DHBA biosynthetic pathway, angB, encoded on the pJM1-like plasmid pJHC1 was required to complement strain S531A-1 (Welch et al. 2000). Recently a partial sequence of an open reading frame (orf) with homology to the plasmid-encoded ang $B$ gene was identified in the chromosomal DNA of $V$. anguillarum 775 within the vancrobactin gene cluster (Alice et al. 2005; Naka et al. 2008). Completion of the nucleotide sequence of the chromosomal gene revealed an orf of 1038 bp that encodes a predicted protein with $64 \%$ identity and $78 \%$ similarity to the plasmid-encoded AngB. The chromosomally encoded AngB-homologue (VabB) of 775 possesses the isochorismate lyase (ICL) and the aryl carrier protein (ArCP) domains that are also found in the plasmid-encoded AngB (Fig. 1a). ICL domains are involved in DHBA biosynthesis and catalyze the conversion of isochorismic acid to 2,3-dihydro 2,3-dihydroxybenzoic acid
(Rusnak et al. 1990). The ArCP domain is the domain required for tethering of activated DHBA and thus required for siderophore biosynthesis (Gehring et al. 1997; Welch et al. 2000).

Sequencing of the same chromosomal locus of $V$. anguillarum 531A showed that the same orf is present in this strain but a deletion of a base at the $5^{\prime}$-end of the gene resulted in premature termination of translation. As shown in Fig. 1b, in 531A the predicted product of the $v a b B$ gene is only 94 amino acids long. Welch et al. (2000) previously showed that in $531 \mathrm{~A}$ the $a n g B$ gene is required for DHBA and anguibactin production, thus the frame-shift generated by the base deletion in the chromosomal $v a b B$ gene of 531A resulted in the plasmid-encoded AngB becoming essential for DHBA production.

Mutational analysis of the $\operatorname{ang} B$ gene in strain 775

To test the functionality of the $v a b B$ gene in strain 775 we generated a mutant, $775(\mathrm{pJM} 1:: \Omega)$, consisting of the insertion of the $\Omega$ transcriptional-translational terminator (Frey and Krisch 1985) at the BglII site in the $5^{\prime}$-end of the $a n g B$ gene (Fig. 2). This mutant was tested for its ability to produce DHBA by the Arnow test, specific for catechols, and the results were confirmed by bioassay using Salmonella strains enb-1 and $e n b-7$ that require DHBA and/or enterobactin to grow in iron limiting conditions. Anguibactin production was determined by CAS agar (data not shown) and growth in iron limiting conditions. To confirm that the iron-binding compound detected on CAS agar is actually anguibactin, bioassays employing strains CC9-8(pJHC9-8) and CC9-16(pJHC9-16) were performed as explained in the "Materials and methods" section. As shown in Fig. 2, strain $775(\mathrm{pJM} 1:: \Omega)$ did not produce anguibactin but it was still able to produce DHBA. Since it is known that in strain 531A, the ArCP domain of AngB can be produced as a polypeptide separate from the ICL domain, a strategy was designed to mutate only the ICL domain. Mutant 775 (pJM1::K) is a 4 bp insertion at the $B g l \mathrm{II}$ site in $\operatorname{ang} B$, generated by cleaving the $B g l \mathrm{II}$ site and filling in the ends with the Klenow fragment of DNA polymerase I prior to re-ligation. This mutant could still produce anguibactin as determined by CAS and bioassay without any DHBA exogenously added to the media since it was able to 


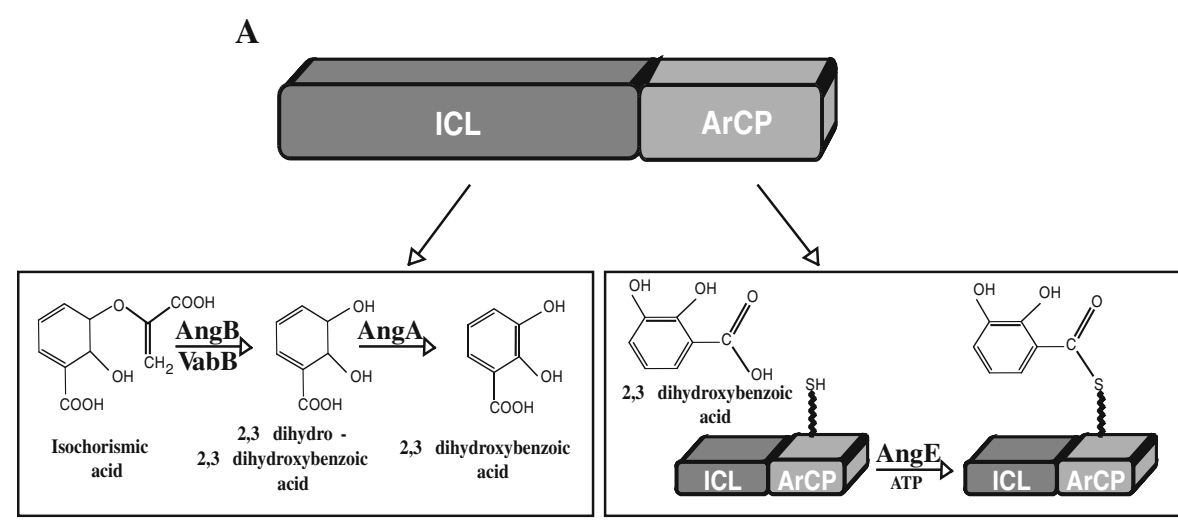

B

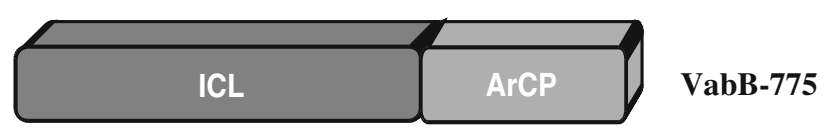

VabB-531A

Fig. 1 Domain organization of plasmid-encoded AngB and chromosomally encoded VabB. A The ICL and ArCP domain organization of the AngB protein of $V$. anguillarum 775 and their putative function in DHBA and anguibactin production, respectively, are shown. B Schematic representation of the predicted $v a b B$ products from $V$. anguillarum 775 and 531A. The 531A VabB possesses only a truncated ICL domain

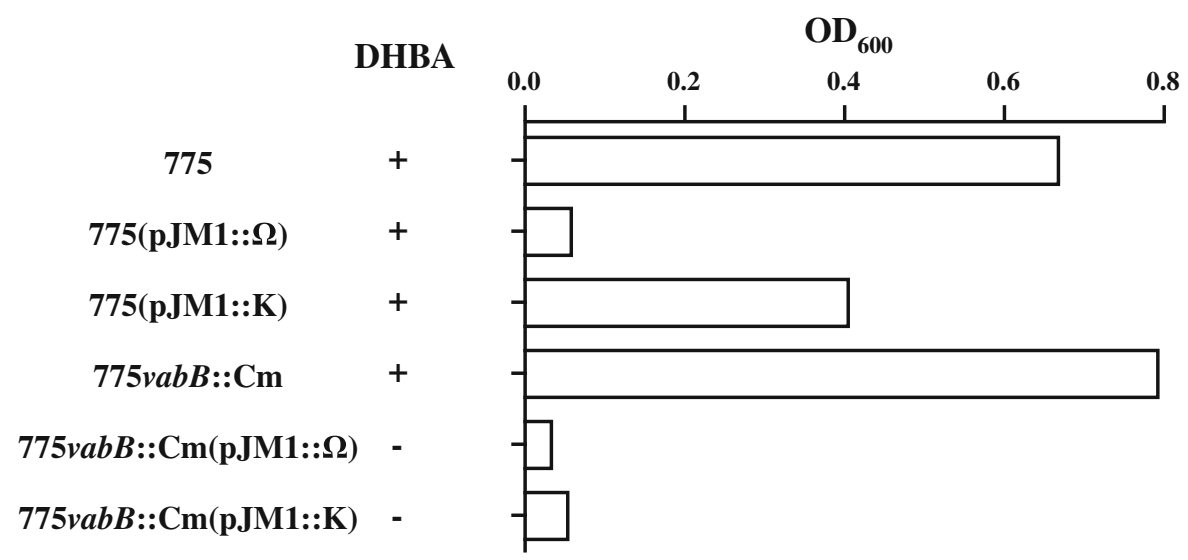

Fig. 2 DHBA and anguibactin production of mutants of the $V$. anguillarum ang $B$ and $v a b B$ genes. The $\operatorname{ang} B, v a b B$ and the double mutants with their phenotype in DHBA and anguibactin production are shown and compared to the wild type strain. Presence of DHBA in the supernatant of cultures grown in iron-limiting conditions was analyzed by using the Arnow reaction and confirmed by bioassays with Salmonella strain

produce DHBA endogenously (Fig. 2). Therefore, the ICL domain of VabB in 775 must be functional although not essential while the ArCP of AngB is essential for anguibactin biosynthesis. Furthermore, $e n b-1$ and enb-7. Anguibactin production by the different strains was detected by CAS agar, bioassays and growth in iron limiting conditions. The results obtained for the growth in iron limiting conditions are represented as the $\mathrm{OD}_{600}$ at $48 \mathrm{~h}$ of each strain grown in M9 supplemented with $2 \mu$ M EDDA. Shown is a representative growth experiment

the results obtained with mutant $775(\mathrm{pJM} 1: \mathrm{K})$ indicate that also in 775 the plasmid-encoded ArCP domain can be translated and function independently of the ICL domain. 
Mutational analysis of the $v a b B$ gene

and generation of double angB/vabB mutant in strain 775

To confirm that the $v a b B$ gene product is only functional in DHBA production and that the AngB protein possesses the only $\mathrm{ArCP}$ domain involved in anguibactin biosynthesis, we generated a mutation in the $v a b B$ gene by replacing almost the complete gene with a chloramphenicol resistance gene as explained in the "Materials and methods" section. The $v a b B$ gene was replaced by the $v a b B:: \mathrm{Cm}$ construct in 775 , $775(\mathrm{pJM} 1:: \Omega)$ and $775(\mathrm{pJM} 1:: \mathrm{K})$ at its chromosomal location in each strain and the resulting derivatives analyzed for DHBA and anguibactin production. Anguibactin was determined by CAS agar, bioassay and growth of the strains in minimal media supplemented with $2 \mu \mathrm{M}$ ethylenediamine-di-(o-hydroxyphenyl acetic acid), EDDA. The presence of DHBA in the supernatant was determined as described above for the $\operatorname{ang} B$ mutants. Strain $775(\mathrm{pJM} 1:: \Omega$ ) although not able to synthesize anguibactin can still produce DHBA (Fig. 2). Strain 775vabB::Cm and strain $775(\mathrm{pJM} 1:: \mathrm{K})$ are not affected in DHBA and in anguibactin production, while both double mutants, $775 v a b B: \mathrm{Cm}(\mathrm{pJM} 1:: \Omega)$ and $775 v a b B: \mathrm{Cm}(\mathrm{pJM} 1:: \mathrm{K})$, are unable to produce either compound (Fig. 2). As expected, addition of DHBA to the growth media restored siderophore production in strain $775 \mathrm{vabB}:$ : Cm(pJM1::K), data not shown. Clearly both ICL domains function in the synthesis of DHBA and they are the only two ICL domains present in strain 775 involved in the production of DHBA, an essential precursor of anguibactin. This product can then be incorporated in the siderophore only by the plasmidencoded ArCP domain.

Characterization of the VabB and AngB functions in vivo

The ang $B$ and $v a b B$ genes from $V$. anguillarum were cloned in vector pBR322 or its derivative pTW99 downstream of the tetracycline resistance gene promoter generating $\mathrm{pAngB}$ and $\mathrm{pVabB}$, respectively. To analyze the functionality of both domains, we mutated conserved residues in the ICL and ArCP domain by site-directed mutagenesis. In the ICL domain the residue to be mutated was chosen based on an alignment of this domain with several other ICL domains. In the isochorismate lyase PhzD from Pseudomonas aeruginosa, an aspartic acid residue in the active site is essential for 2,3-dihydro-3-hydroxyanthranilic acid production from 2-amino-2-deoxyisochorismate (Parsons et al. 2003). The PhzD protein possesses only an ICL domain and it is involved in the biosynthesis of phenazine (Parsons et al. 2003). The same aspartic acid and several surrounding residues are conserved in AngB and VabB as well as in the ICL domain of several enzymes involved in DHBA production (Fig. 3). This conserved aspartic acid residue was mutated to an alanine in the construct harboring either the ang $B$ or the $v a b B$ gene generating the constructs pAngBD37A and pVabB-D71A, respectively. In the ArCP domain of AngB, the residue mutated to an alanine was the conserved serine (S248) that has been shown for the AngB protein of strain 531A to be essential for the attachment of the phosphopantetheinyl arm (Welch et al. 2000). Since we have shown that the ArCP domain of VabB is not functional in anguibactin production, we did not mutate this domain, although it is worthy to note that a conserved serine (S283) in the chromosomally encoded VabB corresponds to the serine residue 248 of AngB and to the conserved serine residue of other ArCP domains (Fig. 3).

The wild type and mutant constructs were used to complement strain AN192 (an E. coli entB mutant) as well as the plasmid terminator mutant $775(\mathrm{pJM} 1:: \Omega)$ and the double angB/vabB mutant of $V$. anguillarum.

The E. coli strain AN192 can be complemented for DHBA production by both wild type $\operatorname{ang} B$ and $\checkmark a b B$ genes of $V$. anguillarum (Fig. 4a). Strain AN192 complemented with pAngB or pVabB were demonstrated to produce enterobactin as determined by growth in iron-limiting conditions and by bioassay with the Salmonella strains (Fig. 4a). Enterobactin production in strain AN192 does not require the ArCP domain of AngB since the mutation in ent $B$ in this strain affects only the functionality of the ICL domain of EntB and not of its ArCP domain (Staab and Earhart 1990). The ICL D to A mutants in either of the pAngB or pVabB constructs were not able to complement strain AN192, clearly showing that the aspartic acid residue is indeed essential for the activity of the ICL domain of both proteins (Fig. 4a). 


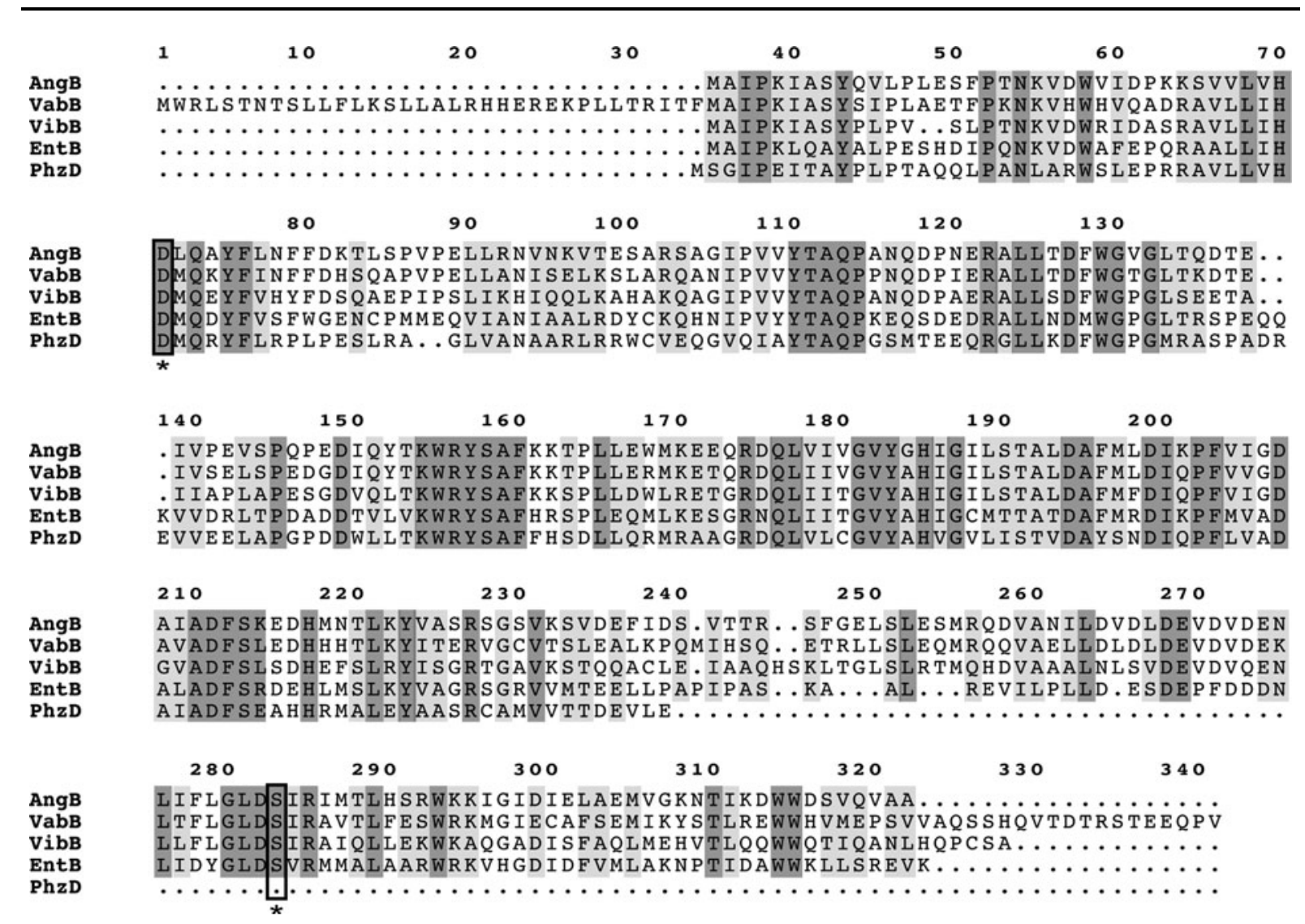

Fig. 3 Multiple sequence alignment of isochorismate lyase enzymes. All the proteins in this alignment except PhzD participate in DHBA biosynthesis as well as in siderophore biosynthesis. PhzD possesses only the ICL domain and it is involved in the biosynthesis of phenazine. The identical

Complementation of both $V$. anguillarum mutants with pAngB restores anguibactin production while strains containing $\mathrm{pVabB}$ still cannot produce the siderophore; nevertheless both constructs in the double mutant restored DHBA production (Fig. 4b). As it was the case in E. coli, the ICL mutant constructs could not complement the double $V$. anguillarum mutant for DHBA production (Fig. 4b). Furthermore, the ArCP mutant in AngB (pAngB-S248A) could not complement strain $775(\mathrm{pJM} 1:: \Omega)$ for anguibactin production although it was able to restore DHBA production in strain $775 \mathrm{vabB}:: \mathrm{Cm}(\mathrm{pJM} 1:: \Omega$ ) (Fig. $4 \mathrm{~b}$ and data not shown). These results further confirm that the ArCP domain of AngB is the only one that can tether DHBA to be utilized in anguibactin production while either of the plasmid or chromosomal ICL domain can intervene in DHBA production. residues are shown shaded in darker grey while similar amino acids are shaded in lighter grey. The two conserved residues in the ICL and ArCP domains that have been selected to be replaced by an alanine in the AngB or VabB proteins are boxed and indicated with an asterisk

Activities of the ICL and ArCP domain of AngB in vitro

To assess the functionality in vitro of the AngB domains, we over-expressed the wild type and the mutant proteins as $C$-terminal His-tagged proteins in $E$. coli as described in the "Materials and methods" section.

To determine ICL activity, an L-lactate dehydrogenase-coupled assay was used in which pyruvate concentration in the reaction mixture was calculated from the amount of NADH oxidized, measured by the decrease of absorbance at $340 \mathrm{~nm}$ (Rusnak et al. 1990). In the reaction that converts isochorismate to 2,3-dihydro-2,3-dihydroxybenzoic acid catalyzed by ICL domains, pyruvate is produced in equimolar amounts with 2,3-dihydro-2,3-dihydroxybenzoic acid 
Fig. 4 Complementation of the ent $B$ mutant of $E$. coli and the mutants of $V$. anguillarum 775.

A Complementation of the E. coli entB mutant AN92 with the wild type and mutant constructs of ang $B$ and $v a b B$ of $V$. anguillarum. The ability to produce DHBA and enterobactin of each strain is measured as the ability to grow in ironlimiting conditions and by bioassay with the Salmonella strains enb1 and enb7. Shown is a representative growth experiment. B The phenotypes in DHBA and anguibactin production of the complemented angB mutants are shown and compared to the wild type strain. DHBA production was measured by the Arnow test on supernatant of cultures grown in ironlimiting conditions. Growth in iron-limiting conditions (minimal media supplemented with $2 \mu \mathrm{M}$ EDDA) is used to determine the ability of each strain to produce anguibactin. Shown is a representative growth experiment
A

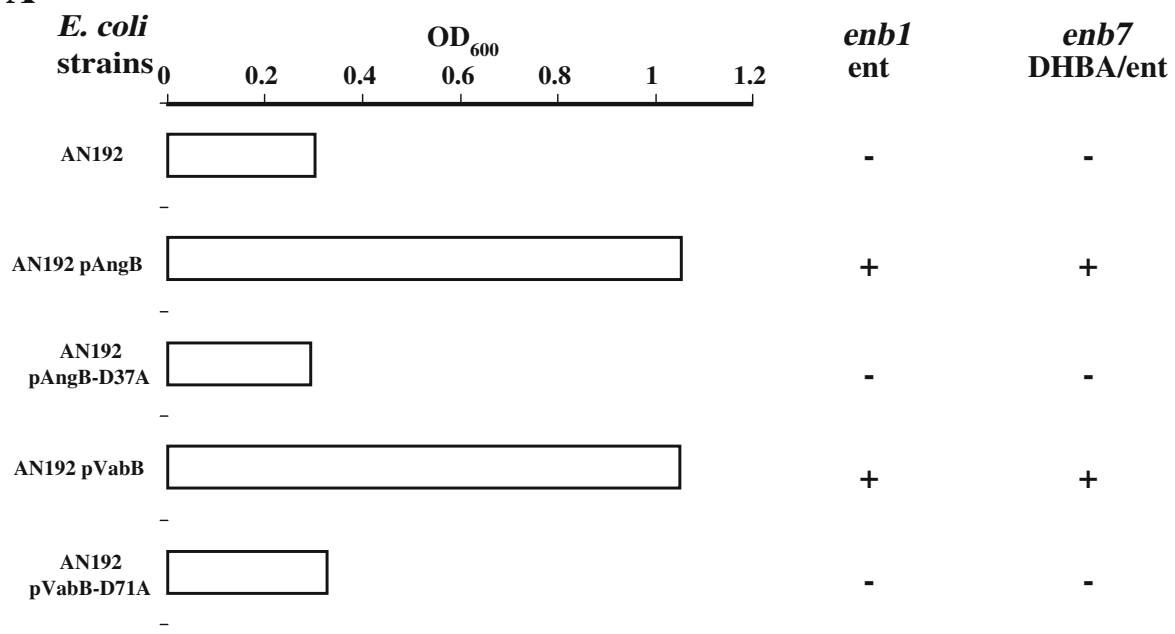

B

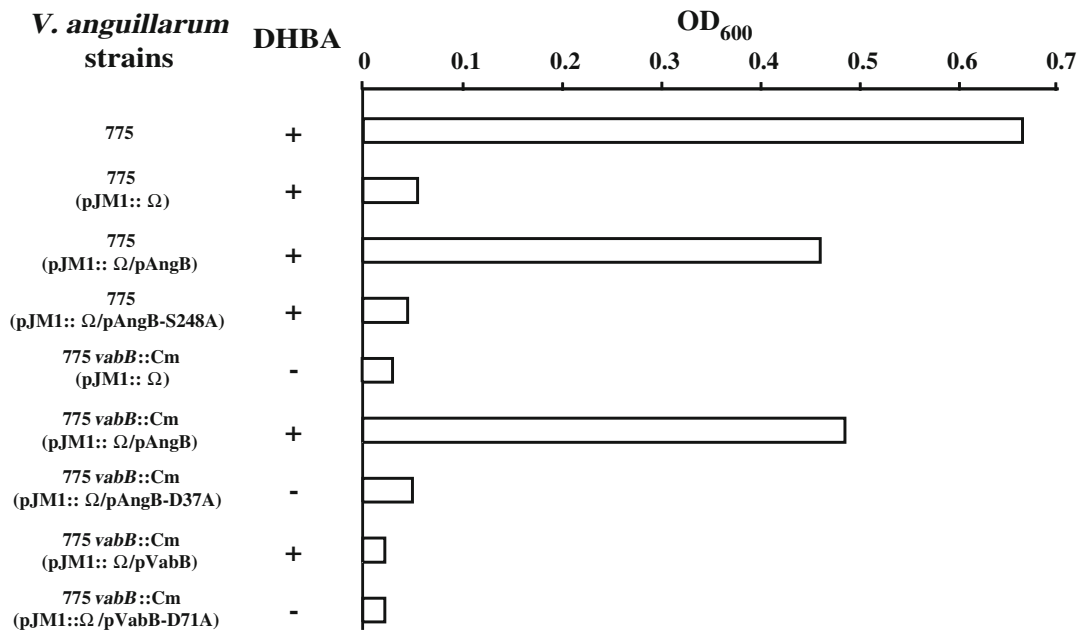

(Fig. 5a). As shown in Fig. 5b, NADH was completely oxidized to $\mathrm{NAD}^{+}$in the reaction containing wild type AngB or the ArCP mutant protein. On the contrary the ICL mutant protein behaved as the noICL sample in the oxidation of NADH confirming the results obtained in vivo for this mutant protein (Fig. 5b).

Functionality of the ArCP domain was determined by in vitro salicylation with ${ }^{14} \mathrm{C}$ labeled salicylate of the purified proteins (Marshall et al. 2002). Although the wild type AngB protein purified from E. coli is obtained partially in its holo form, i.e. with the phosphopantetheine arm already tethered to the ArCP domain (data not shown), holo-ArCP was formed in vitro prior to the salicylation reaction by incubation with the phosphopantetheinyl transferase of Bacillus subtilis, Sfp (Quadri et al. 1998) and coenzymeA (CoA). Figure 6 shows that the wild type AngB protein as well as the ICL mutant can be salicylated in vitro to similar extent while the percentage of the ArCP S248A mutant labeled with $\left[{ }^{14} \mathrm{C}\right]$ salicylate is similar to that of the sample in which no adenylation domain (VibE) was added. These results are in agreement with the results obtained for the AngBS248A mutant in anguibactin production in vivo.

\section{Discussion}

The iron uptake system mediated by the plasmid pJM1 is composed by the $348 \mathrm{Da}$ siderophore anguibactin that is synthesized from DHBA, cysteine 
Fig. 5 In vitro ICL reaction with purified wild type and mutant AngB proteins. A Scheme of the in vitro ICL reaction. Isochorismic acid, the substrate for AngB is obtained from chorismic acid by addition of purified EntC protein. Production of pyruvate from isochorismic acid is measured as the oxidation of NADH by L-lactate dehydrogenase in the reaction mix.

B Production of pyruvate expressed as nanomoles is plotted over time for each AngB protein. Each point is calculated as the mean of three independent experiments in which the same amount of proteins and substrate were used.

The error bars indicate the standard error of the mean (SEM)

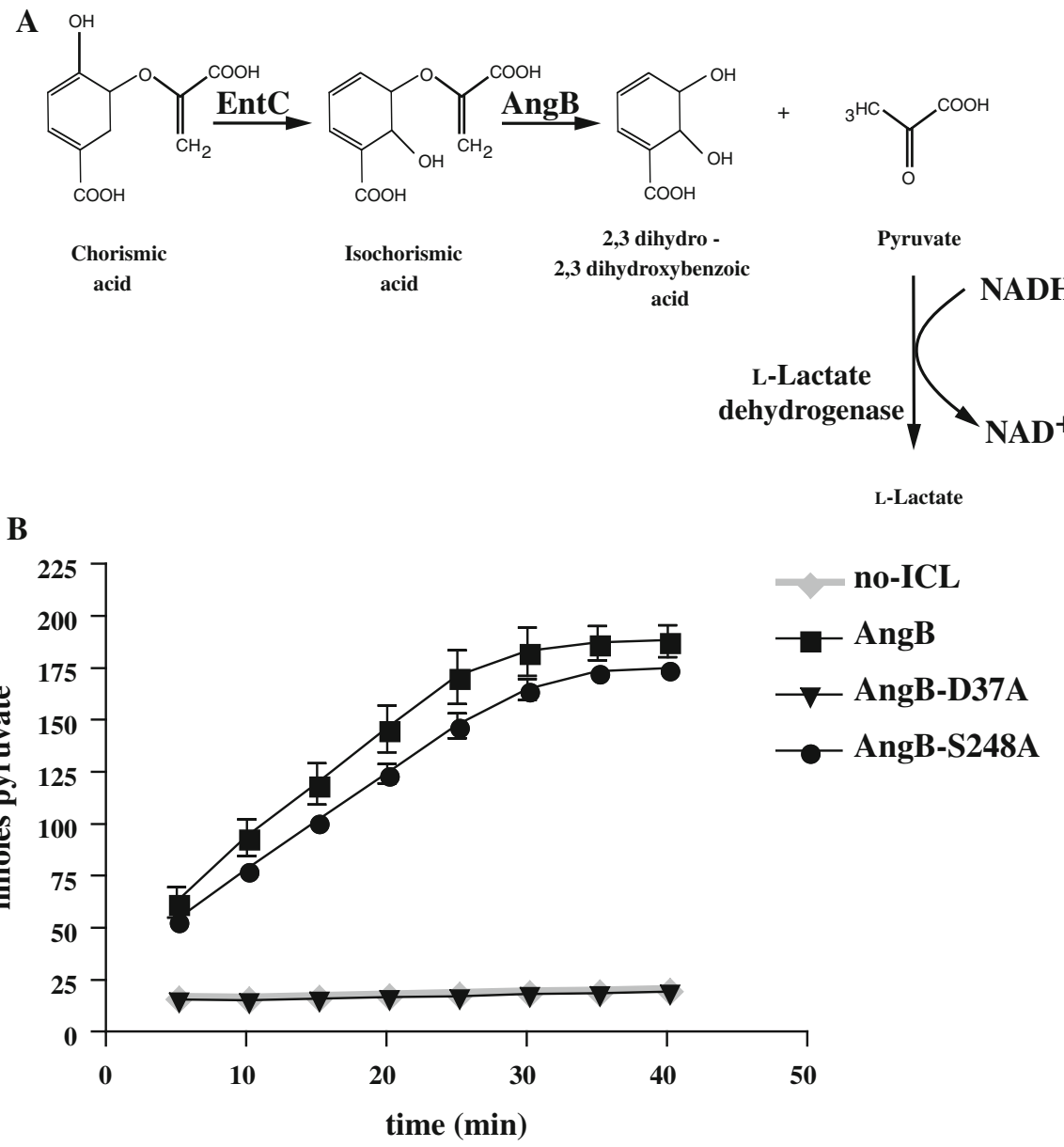

and hydroxyhistamine, and a membrane receptor complex specific for ferric-anguibactin. This system is an important virulence factor for the fish pathogen V. anguillarum (Wolf and Crosa 1986).

Sequencing of the pJM1 plasmid of strain 775 revealed a gene cluster (orf39 to 43) that encodes products that share homology with proteins involved in synthesis and activation of DHBA (Di Lorenzo et al. 2003). A similar cluster was identified on the pJM1-like plasmid pJHC1 of strain 531A and it was shown that the $\operatorname{ang} B$ gene (orf4l) in this cluster is essential for DHBA and anguibactin production in this strain (Welch et al. 2000). One interesting difference between these two $V$. anguillarum strains was revealed by the study of their plasmidless derivatives. H775-3, the 775 derivative, is proficient in DHBA production while S531A-1, the 531A derivative, is not. Therefore, we hypothesized that an additional copy of the ang $B$ gene might be present on the chromosome of strain 775 . We identified an orf with homology to the plasmid-encoded angB gene in the chromosomal DNA of $V$. anguillarum 775 within the vanchrobactin cluster. Sequencing of this orf revealed that it encoded a protein $78 \%$ similar and $64 \%$ identical to the plasmid-encoded AngB, although 57 amino acids longer. The predicted amino acid sequence of the chromosomal homologue includes the ICL and ArCP domains as it is the case for the AngB protein. Surprisingly, the same sequence was found on the 531A chromosomal DNA but deletion of a base at the $5^{\prime}$-end resulted in a non-functional truncated protein as the truncation occurs in the ICL domain before the conserved residues of the active site.

Furthermore, in this work we also characterized the two homologues of 775 and assessed their functions by a combination of knock-out and sitedirected mutations. We clearly showed that the ArCP 


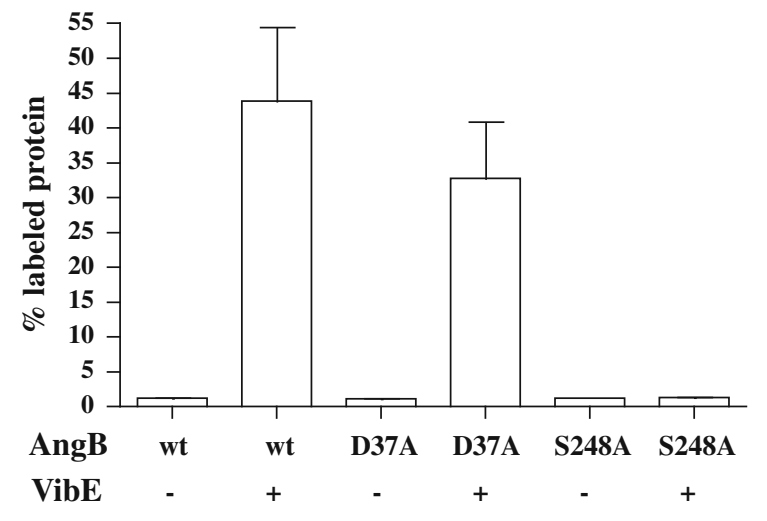

Fig. 6 In vitro salicylation reaction with purified wild type and mutant AngB proteins. The percentage of ArCP domain labeled with $\left[{ }^{14} \mathrm{C}\right]$-salicylate is shown with each bar calculated from the mean of three independent experiments in which the same amounts of proteins and substrate where used. As controls each AngB protein was incubated without the adenylating enzyme VibE. The means for the wild type and the D37A mutant AngB proteins are not significantly different when compared by the $t$-test at $P \leq 0.05(P=0.45)$. The error bars indicate the standard error of the mean of the results from replicate samples. wt, wild type AngB; D37A, D37A mutant of AngB; S248A, S248A mutant of AngB

domain of the plasmid-encoded copy is essential for anguibactin biosynthesis, while the ICL domain of either the chromosomal or the plasmid homologue can be used in DHBA production. The two ICL domains can also complement an $E$. coli ent $B$ mutant for DHBA production.

Site-directed mutagenesis of the ICL domain of the two proteins of 775 confirmed that the active site of this domain corresponds to the active site of $\mathrm{PhzD}$, an isochorismate lyase that is not part of the DHBA biosynthetic pathway and is not associated with an ArCP domain (Parsons et al. 2003). In vitro experiments with the purified plasmid-encoded AngB protein demonstrated that the site-directed mutant in the ICL domain was affected in the isochorismate lyase activity but its ArCP domain could still be loaded with $\left[{ }^{14} \mathrm{C}\right]$-salicylate as it is the case for the wild type protein. The same was true for the ArCP domain mutant (S248A), whose ability to convert isochorismate to 2,3-dihydro-dihydroxybenzoic acid was not altered while the loading of $\left[{ }^{14} \mathrm{C}\right]$-salicylate was completely abolished. Thus, the in vitro results confirmed those obtained in vivo in $V$. anguillarum and E. coli. Furthermore, the in vitro experiments with the site-directed mutants (D37A and S248A) clearly showed the importance of each residue for the domain function.
The identification and characterization of the chromosomally encoded homologue $v a b B$ add another chapter to the complex tale of the ironuptake systems of $V$. anguillarum species. The chromosomally encoded gene lies within a cluster of other genes dedicated to DHBA biosynthesis and activation and these genes have been shown to be part of the vanchrobactin biosynthetic pathway (Alice et al. 2005; Balado et al. 2006; Naka et al. 2008). Naka et al. (2008) showed that the ArCP of VabB perfectly functions in vanchrobactin assembly line. The fact that this clearly functional ArCP domain is not able to participate in anguibactin production suggests a system specificity of the AngB-ArCP domain for the anguibactin system.

In the enterobactin system, three residues have been identified that, when mutated, result in a decreased rate of enterobactin production (Lai et al. 2006). Two of these residues map within helix 3 of EntB crystal structure and helix 3 is suggested to be the major recognition element on EntB-ArCP domain for EntF, the downstream elongation module (Drake et al. 2006; Lai et al. 2006). AngB-ArCP and VabBArCP homology models were generated using 3D JIGSAW web server (Bates et al. 2001). Interestingly, the two models differ in helix 3 where AngB-ArCP seems to lack in the model a helix 3 and to have a longer helix 2, whereas the VabB-ArCP domain shows a 4 helices model highly similar to the EntB structure. As a consequence, we propose that other recognition elements in the ArCP domain are required for the interaction of AngB with AngM, the downstream module (Di Lorenzo et al. 2004b). The proposed difference in the interaction-surface of the two ArCP domains could explain the inability of the VabB-ArCP domain to function in anguibactin production.

Furthermore, short $\mathrm{N}$-terminal and $\mathrm{C}$-terminal sequences have been shown to be involved in protein-protein interactions in the NRPS family (Hahn and Stachelhaus 2004). The VabB protein presents amino acid extensions at both ends when compared with the other homologues including $V$. anguillarum AngB and these extra sequences at the $N$ - and $C$-terminus could be the specific signature of the vanchrobactin system that prevent VabB from interacting with the other proteins of the anguibactin system. The system specificity of the anguibactin pathway does not apply to DHBA biosynthesis since 
the ICL domain activity seems to be independent of the other enzymes and strain background.

Acknowledgments This project was supported by Grants from the National Institute of Health, AI19018 and GM64600, to J.H.C. We are grateful to Christopher T. Walsh for his insightful discussions and the VibE and Sfp expression constructs.

\section{References}

Actis LA, Tolmasky ME, Farrell DH, Crosa JH (1988) Genetic and molecular characterization of essential components of the Vibrio anguillarum plasmid-mediated iron-transport system. J Biol Chem 263:2853-2860

Actis LA, Tolmasky ME, Crosa JH (1999) Vibriosis. In: Woo P, Bruno D (eds) Fish diseases and disorders. Viral, bacterials, and fungal infections, vol. 3. Cab International Publishing, Wallingford, pp 523-557

Alice AF, Lopez CS, Crosa JH (2005) Plasmid- and chromosome-encoded redundant and specific functions are involved in biosynthesis of the siderophore anguibactin in Vibrio anguillarum 775: a case of chance and necessity? J Bacteriol 187:2209-2214

Altschul SF, Gish W, Miller W, Myers EW, Lipman DJ (1990) Basic local alignment search tool. J Mol Biol 215:403-410

Arnow EL (1937) Colorimetric determination of the components of 2, 3-dihydroxy-phenylalanine tyrosine mixtures. J Biol Chem 118:531-537

Balado M, Osorio CR, Lemos ML (2006) A gene cluster involved in the biosynthesis of vanchrobactin, a chromosome-encoded siderophore produced by Vibrio anguillarum. Microbiology 152:3517-3528

Bates PA, Kelley LA, MacCallum RM, Sternberg MJE (2001) Enhancement of protein modelling by human intervention in applying the automatic programs 3D-JIGSAW and 3DPSSM. Proteins 5:39-46

Bolivar F (1978) Construction and characterization of new cloning vehicles. III. Derivatives of plasmid pBR322 carrying unique Eco RI sites for selection of Eco RI generated recombinant DNA molecules. Gene 4:121-136

Boyer HW, Roulland-Dussoix D (1969) A complementation analysis of the restriction and modification of DNA in Escherichia coli. J Mol Biol 41:459-472

Chen Q, Actis LA, Tolmasky ME, Crosa JH (1994) Chromosome-mediated 2, 3-dihydroxybenzoic acid is a precursor in the biosynthesis of the plasmid-mediated siderophore anguibactin in Vibrio anguillarum. J Bacteriol 176:42264234

Conchas RF, Lemos ML, Barja JL, Toranzo AE (1991) Distribution of plasmid- and chromosome-mediated iron uptake systems in Vibrio anguillarum strains of different origins. Appl Environ Microbiol 57:2956-2962

Crosa JH (1980) A plasmid associated with virulence in the marine fish pathogen Vibrio anguillarum specifies an ironsequestering system. Nature 284:566-568

Crosa JH, Hodges LL, Schiewe MH (1980) Curing of a plasmid is correlated with an attenuation of virulence in the marine fish pathogen Vibrio anguillarum. Infect Immun 27:897-902

Datsenko KA, Wanner BL (2000) One-step inactivation of chromosomal genes in Escherichia coli K-12 using PCR products. Proc Natl Acad Sci USA 97:6640-6645

Di Lorenzo M, Stork M, Tolmasky ME, Actis LA, Farrell DH, Welch TJ, Crosa LM, Wertheimer AM, Chen Q, Salinas P, Waldbeser L, Crosa JH (2003) Complete sequence of virulence plasmid pJM1 from the marine fish pathogen Vibrio anguillarum strain 775. J Bacteriol 185:5822-5830

Di Lorenzo M, Stork M, Alice AF, López CS, Crosa JH (2004a) Vibrios. In: Crosa JH, May A, Payne SM (eds) Iron transport in bacteria: molecular biology, physiology and ecology. ASM press, Washington

Di Lorenzo M, Poppelaars S, Stork M, Nagasawa M, Tolmasky ME, Crosa JH (2004b) A nonribosomal peptide synthetase with a novel domain organization is essential for siderophore biosynthesis in Vibrio anguillarum. J Bacteriol 186:7327-7336

Drake EJ, Nicolai DA, Gulick AM (2006) Structure of the EntB multidomain nonribosomal peptide synthetase and functional analysis of its interaction with the EntE adenylation domain. Chem Biol 13:409-419

Figurski DH, Helinski DR (1979) Replication of an origincontaining derivative of plasmid RK2 dependent on a plasmid function provided in trans. Proc Natl Acad Sci USA 76:1648-1652

Frey J, Krisch HM (1985) Omega mutagenesis in gram-negative bacteria: a selectable interposon which is strongly polar in a wide range of bacterial species. Gene 36:143-150

Gehring AM, Bradley KA, Walsh CT (1997) Enterobactin biosynthesis in Escherichia coli: isochorismate lyase (EntB) is a bifunctional enzyme that is phosphopantetheinylated by EntD and then acylated by EntE using ATP and 2, 3-dihydroxybenzoate. Biochemistry 36:8495-8503

Hahn M, Stachelhaus T (2004) Selective interaction between nonribosomal peptide synthetases is facilitated by short communication-mediating domains. Proc Natl Acad Sci USA 101:15585-15590

Jalal M, Hossain D, van der Helm D, Sanders-Loehr J, Actis LA, Crosa JH (1989) Structure of anguibactin, a unique plasmid-related bacterial siderophore from the fish pathogen Vibrio anguillarum. J Am Chem Soc 111:292-296

Keating TA, Marshall CG, Walsh CT (2000) Reconstitution and characterization of the Vibrio cholerae vibriobactin synthetase from VibB, VibE, VibF, and VibH. Biochem 39:15522-15530

Lai JR, Fischbach MA, Liu DR, Walsh CT (2006) A protein interaction surface in nonribosomal peptide synthesis mapped by combinatorial mutagenesis and selection. Proc Natl Acad Sci USA 103:5314-5319

Marshall CG, Burkart MD, Meray RK, Walsh CT (2002) Carrier protein recognition in siderophore-producing nonribosomal peptide synthetases. Biochem 41:8429-8437

Naka H, López CS, Crosa JH (2008) Reactivation of the vanchrobactin siderophore system of Vibrio anguillarum by removal of a chromosomal insertion sequence originated in plasmid pJM1 encoding the anguibactin siderophore system. Environ Microbiol 10:265-277 
Notredame C, Higgins DG, Heringa J (2000) T-coffee: a novel method for multiple sequence alignments. J Mol Biol 302:205-217

Parsons JF, Calabrese K, Eisenstein E, Ladner JE (2003) Structure and mechanism of Pseudomonas aeruginosa $\mathrm{PhzD}$, an isochorismatase from the phenazine biosynthetic pathway. Biochemistry 42:5684-5693

Pollack JR, Neilands JB (1970) Enterobactin, an iron transport compound from Salmonella typhimurium. Biochem Biophys Res Commun 38:989-992

Quadri LE, Weinreb PH, Lei M, Nakano MM, Zuber P, Walsh CT (1998) Characterization of Sfp, a Bacillus subtilis phosphopantetheinyl transferase for peptidyl carrier protein domains in peptide synthetases. Biochemistry 37:1585-1595

Rusnak F, Liu J, Quinn N, Berchtold GA, Walsh CT (1990) Subcloning of the enterobactin biosynthetic gene entB: expression, purification, characterization, and substrate specificity of isochorismatase. Biochemistry 29:1425-1435

Sambrook J, Russell DW (2001) Molecular cloning: a laboratory manual, 3rd edn. Cold Spring Harbor Laboratory Press, Cold Spring Harbor

Schwyn B, Neilands JB (1987) Universal chemical assay for the detection and determination of siderophores. Anal Biochem 160:47-56

Staab JF, Earhart CF (1990) EntG activity of Escherichia coli enterobactin synthetase. J Bacteriol 172:6403-6410
Stork M, Di Lorenzo M, Mourino S, Osorio CR, Lemos ML, Crosa JH (2004) Two tonB systems function in iron transport in Vibrio anguillarum, but only one is essential for virulence. Infect Immun 72:7326-7329

Tolmasky ME, Actis LA, Crosa JH (1988a) Genetic analysis of the iron uptake region of the Vibrio anguillarum plasmid pJM1: molecular cloning of genetic determinants encoding a novel trans activator of siderophore biosynthesis. J Bacteriol 170:1913-1919

Tolmasky ME, Salinas PC, Actis LA, Crosa JH (1988b) Increased production of the siderophore anguibactin mediated by pJM1-like plasmids in Vibrio anguillarum. Infect Immun 56:1608-1614

Walter MA, Potter SA, Crosa JH (1983) Iron uptake system mediated by Vibrio anguillarum plasmid pJM1. J Bacteriol 156:880-887

Welch TJ, Chai S, Crosa JH (2000) The overlapping angB and ang $G$ genes are encoded within the trans-acting factor region of the virulence plasmid in Vibrio anguillarum: essential role in siderophore biosynthesis. J Bacteriol 182:6762-6773

Wolf MK, Crosa JH (1986) Evidence for the role of a siderophore in promoting Vibrio anguillarum infections. J Gen Microbiol 132:2949-2952 